\title{
Herança da resistência quantitativa à ferrugem da folha em linhagens recombinantes de aveia branca
}

\author{
Caroline L. Wesp ${ }^{1}$, José A. Martinelli ${ }^{1}$, Márcia S. Chaves ${ }^{2}$, Felipe A.S. Graichen ${ }^{1}$ \& Luiz C. Federizzi ${ }^{1}$ \\ ${ }^{1}$ Faculdade de Agronomia, Universidade Federal do Rio Grande do Sul, Cx. Postal 776, 91540-000, Porto Alegre, RS, Brasil; \\ ${ }^{2}$ Embrapa Trigo, Cx. Postal 451, 99001-970, Passo Fundo, RS, Brasil
}

Autor para correspondência: José A. Martinelli, e-mail: jamfito@ufrgs.br

\begin{abstract}
RESUMO
A resistência quantitativa à ferrugem da folha da aveia está sendo preconizada em programas de melhoramento genético na busca de uma resistência mais durável, pois exerce menor pressão de seleção para virulência sobre a população patogênica do que a resistência qualitativa. Este tipo de resistência é o resultado da combinação de componentes como: longo período latente, curto período infeccioso, baixa eficiência de infecção e pústulas de comprimento reduzido. Neste patossistema, entretanto, não se sabe ao certo o papel individual de cada um destes componentes sobre o desenvolvimento da doença, bem como, o número de genes que determinam sua expressão. Assim, este trabalho visou caracterizar aspectos da herança da resistência à ferrugem da folha em 83 linhagens recombinantes $F_{6: 10}$ de aveia branca, oriundas do cruzamento de UFRGS 7 (suscetível) com UFRGS 910906 (com resistência quantitativa). Os resultados indicam que esta resistência é de natureza poligênica e parece ser governada por vários genes de pequeno efeito, sendo que sua expressão fenotípica é resultado da ação conjunta de mais de um componente.
\end{abstract}

Palavras-chave: Puccinia coronata f. sp. avenae, Avena sativa, componentes de resistência, genes menores.

\begin{abstract}
Inheritance of quantitative resistance to crown rust in recombinant lines of white oat

Quantitative resistance to oat crown rust is being praised in breeding programs in search of more durable resistance because it exerts less selection pressure for virulence on the pathogenic population than does qualitative resistance. This type of resistance results from the combination of components such as: long latency period, short period of infection, low infection efficiency and pustules of reduced length. However, in this pathosystem the individual role of each component in disease development is not known, and nor are the number of genes that control these traits. This work aimed to characterize some aspects of the inheritance of quantitative resistance to crown rust in $83 \mathrm{~F}_{6: 10}$ white oat recombinant lines from the UFRGS 7 (susceptible) x UFRGS 910906 (quantitative resistance) cross. The results indicate that this resistance is of a polygenic nature; it seems to be governed by several genes of small effect, and its expression results from the combined effect of more than one component.
\end{abstract}

Keywords: Puccinia coronata f. sp. avenae, Avena sativa, components of resistance, minor genes.

\section{INTRODUÇÃO}

O aumento da área cultivada com aveia branca (Avena sativa L.) no sul do Brasil trouxe consigo maiores riscos de epidemias. Dentre os principais patógenos que atacam a cultura, destaca-se o fungo causador da ferrugem da folha (Puccinia coronata f. sp. avenae W.P. Fraser \& Ledingham). Mesmo intensidades pequenas de ferrugem, causam dano significativo, próximo a $50 \mathrm{~kg} / \mathrm{ha}$ para cada $1 \%$ de severidade nos estádios iniciais de desenvolvimento da cultura. Os componentes do rendimento mais afetados são o peso de grãos e o peso médio de panículas. Grãos oriundos de plantas infectadas apresentam-se murchos, com pouco ou

Parte da Dissertação de Mestrado do primeiro autor. Universidade Federal do Rio Grande do Sul. Porto Alegre RS. 2004. nenhum valor comercial e nutricional, além de sofrerem altas taxas de quebra durante o descascamento (Martinelli et al., 1994; Cruz et al., 1999).

A população de $P$. coronata é altamente complexa e especializada, com grande variabilidade genética para virulência. Existem muitas raças fisiológicas do fungo, as quais diferem na habilidade ou inabilidade de atacar diferentes variedades de aveia, e cujas freqüencias populacionais estão em constante mudança. A combinação destes fatores resulta em uma pressão de seleção muito grande sobre a população de $P$. coronata, pois durante todo o ano há uma grande quantidade de inóculo disponível, o que proporciona oportunidades para o surgimento e fixação de isolados mutantes mais virulentos (Leonard \& Martinelli, 2005).

Por este motivo, o uso de resistência qualitativa (completa) não vem sendo uma forma efetiva de controle, em termos de durabilidade, já que cultivares com este tipo de 
resistência são superadas em poucos anos de uso extensivo, tornando-se necessário o desenvolvimento e lançamento constantes de novas cultivares.

Neste contexto, a resistência quantitativa (parcial), condicionada por genes menores, é preconizada como alternativa para obtenção de resistência mais durável, pois não suprime o patógeno, apenas impede que este atinja níveis destrutivos, reduzindo a probabilidade de este sofrer mutações vantajosas ou conseguir, por recombinação, reunir os genes que possibilitem uma infecção vitoriosa (Leonard, 2002; Parlevliet, 1979). A resistência quantitativa caracteriza-se por uma redução na taxa de desenvolvimento da doença, através da combinação dos componentes que a condicionam, como redução na freqüência de infecção, menor comprimento de lesões, períodos de latência mais longos, menores taxas de produção de esporos e menor período infeccioso (Whal et al., 1980).

Segundo Parlevliet (1988), a resistência parcial deve ser avaliada no campo, através da quantificação da proporção do tecido do hospedeiro afetado. Esta medição pode ser realizada uma vez, próximo ao final do ciclo da moléstia (severidade final), ou várias vezes durante o desenvolvimento da epidemia. A primeira representa o resultado acumulado do efeito dos componentes de resistência ao longo do tempo, e a segunda possibilita o cálculo da área abaixo da curva de progresso da doença (ASCPD) e da taxa aparente de infecção $(r)$. Das três formas de avaliação citadas, a última (r) é considerada como claramente inferior às outras duas (severidade final e ASCPD) (Rees et al., 1979a; Rees et al., 1979b; Parlevliet, 1985). A avaliação de componentes de resistência em condições controladas também é recomendada no sentido de minimizar a probabilidade de que a resistência observada em campo seja reflexo da baixa freqüência de raças virulentas do patógeno (Chaves et al., 2004b).

Nos últimos anos, diversos trabalhos têm sido realizados pelo Programa de Melhoramento Genético de Aveia da Faculdade de Agronomia da UFRGS, a fim de identificar linhagens com resistência parcial. Nestes estudos, a linhagem UFRGS 910906 tem se destacado por apresentar baixos valores de ASCPD e uma boa combinação de componentes de resistência favoráveis, quando comparada com cultivares suscetíveis (Thomé, 1999; Tisian et al., 2004; Chaves, 2004a, b, c). A população derivada do cruzamento UFRGS 7 x UFRGS 910906 foi utilizada em estudos através dos quais foram identificados QTL's associados à resistência com potencial para utilização em seleção assistida (Barbosa, 2002). A consistência da resistência parcial conferida por UFRGS 910906 ao longo dos anos tem chamado atenção para a sua potencialidade como fonte de resistência na interação aveia $\mathrm{x}$ ferrugem da folha (Kulcheski et al., 2006).

O objetivo deste trabalho foi caracterizar a herança da resistência à ferrugem da folha em 83 linhagens recombinantes $\mathrm{F}_{6: 10}$ de aveia branca, oriundas do cruzamento de UFRGS 7 (suscetível) com UFRGS 910906 (parcialmente resistente), através do padrão de segregação fenotípica das variáveis ASCPD, taxa de progresso da doença, severidade final e tamanho de pústulas.

\section{MATERIAL E MÉTODOS}

\section{Genótipos de aveia}

Foram avaliadas 83 linhagens de aveia, em $\mathrm{F}_{6: 10}$, provenientes do cruzamento da cultivar UFRGS 7 (suscetível) com a linhagem UFRGS 910906 (parcialmente resistente), realizado pelo Programa de Melhoramento Genético de Aveia da Faculdade de Agronomia da UFRGS. Os pais foram testados juntamente com as linhagens.

\section{Inóculo}

Os experimentos em condições de campo tiveram inoculação natural, a partir de uredosporos de $P$. coronata $\mathrm{f}$. sp. avenae das raças representativas da virulência ocorrente na Região Sul do Brasil. O inóculo utilizado nos testes em condições controladas consistiu de uredosporos do patógeno coletados na Estação Experimental Agronômica da UFRGS (EEA), em Eldorado do Sul, RS, na safra 2003-2004. A coleta foi realizada sobre folhas de diversos genótipos de aveia com auxílio de aspirador de pó portátil, a fim de obter uma mistura de raças do patógeno, resultante de infecções naturais de campo.

\section{Avaliações em condições de campo}

$\mathrm{O}$ ensaio em condições de campo visou quantificar os parâmetros epidemiológicos área sob a curva de progresso da doença (ASCPD), severidade da doença no final do ciclo da cultura e a taxa de progresso da epidemia. As 83 linhagens recombinantes $\mathrm{F}_{6: 10}$ e os dois genitores foram semeados na Estação Experimental Agronômica da UFRGS (EEA), em Eldorado do Sul, RS, no ano de 2004. A semeadura foi realizada em parcelas com duas linhas de 2,0 $\mathrm{m}$ de comprimento, espaçadas entre si em 0,20 m, com o auxílio de uma semeadora de parcelas experimentais. $\mathrm{O}$ delineamento experimental foi de blocos completamente casualizados, com quatro repetições. Foram realizados os tratos culturais recomendados para a cultura da aveia, exceto a aplicação de fungicidas sobre as plantas. A partir do surgimento da ferrugem por infecção natural, foram feitas avaliações semanais de severidade em cada parcela, com auxílio de uma escala diagramática (Stubbs et al., 1986), num total de 10 avaliações. A partir destes dados foi calculada a ASCPD para cada um dos 85 genótipos, através de integração trapezoidal, utilizando a equação:

$$
\mathrm{ASCPD}=\sum_{i=1}^{n}\left(\left[\left(\mathrm{Y}_{i+1}+\mathrm{Y}_{i}\right) \times 0,5\right]\left[\mathrm{T}_{i+1}-\mathrm{T}_{i}\right]\right.
$$

Onde: $\mathrm{Y}_{i}=$ percentagem de área foliar afetada pela ferrugem na $i$-ésima observação, $\mathrm{T}_{i}=$ tempo (em dias) no momento da $i$-ésima observação e $n=$ número total de observações (Shaner \& Finney, 1977). A taxa de progresso da doença ( $r$ ) também foi estimada através dos dados de severidade ao longo do tempo, sendo $r=$ percentagem de área foliar afetada/dia (Chaves et al., 2004a). A severidade no final do ciclo da cultura foi aquela observada no momento da última avaliação realizada. 


\section{Avaliações em condições controladas}

Sob condições controladas, foram quantificados os componentes de resistência: tamanho de pústulas em plântulas e em plantas adultas (câmara climatizada e casa de vegetação, respectivamente), no Departamento de Fitossanidade da Faculdade de Agronomia da UFRGS, durante os anos de 2003 e 2004.

Para a avaliação do tamanho de pústulas em plântulas, os genótipos foram semeados em sementeiras de isopor contendo solo (50\% terra $+50 \%$ areia) peneirado, e mantidos em sala climatizada, com condições controladas de temperatura $\left(20 \pm 2^{\circ} \mathrm{C}\right)$ e luminosidade $(12 \mathrm{~h}$ de luz), na Faculdade de Agronomia da UFRGS. O delineamento experimental utilizado foi inteiramente ao acaso, medindose um total de 50 pústulas por genótipo. A inoculação foi feita 11 dias após a semeadura, quando a primeira folha estava totalmente expandida, através do método da torre de deposição de esporos. Para este tipo de inoculação, as plântulas foram colocadas na base de um cilindro de metal (torre de deposição) medindo 1,2 $\mathrm{m}$ de altura e $0,8 \mathrm{~m}$ de diâmetro, e os esporos soprados para seu interior, através de orifícios de $2 \mathrm{~cm}$ de diâmetro, presentes na parede lateral do cilindro, localizados a $4 \mathrm{~cm}$ da tampa de fechamento do mesmo. As plântulas foram deixadas dentro do cilindro, em câmara úmida, por 14 horas no escuro. Dez dias após a inoculação as folhas foram coletadas e prensadas, sendo as pústulas medidas sob microscópio estereoscópico Leica MZ12 , com lente ocular graduada, sob aumento de 80 vezes.

Para as avaliações do tamanho de pústulas em plantas adultas, os genótipos foram semeados em casa de vegetação com condições semicontroladas, em potes plásticos, com capacidade para $5 \mathrm{~L}$, contendo terra de lavoura, coletada até $5 \mathrm{~cm}$ da superfície do solo, desconsiderando a palhada. Após a emergência, foi feito um desbaste, onde foram deixadas três plantas por pote. No estádio de cinco folhas, foi aplicado o equivalente a $600 \mathrm{~kg} /$ ha de NPK $(5 / 20 / 15)$ na superfície de cada vaso. $\mathrm{O}$ delineamento experimental foi inteiramente ao acaso, com três repetições. Na fase de extrusão de panículas, as plantas foram inoculadas através de aspersão manual com suspensão de uredosporos provenientes do campo, em concentração de $1 \times 10^{9}$ esporos/mL. Quinze dias após a inoculação, foram feitas amostragens das folhas bandeira, bandeira-1 e bandeira- 2 de cada genótipo, a fim de realizar a medição das pústulas presentes. Foram medidas 75 pústulas por genótipo, sendo $25 \mathrm{em}$ cada folha bandeira, sob microscópio estereoscópico Leica MZ-12, com lente ocular graduada, sob aumento de 80 vezes.

\section{Análise estatística}

Os dados de ASCPD, severidade final, taxa de progresso da doença e tamanho de pústulas em plântulas e plantas adultas foram submetidos à análise de variância (ANOVA). Os dados originais sofreram transformação do tipo raiz quadrada de $(x+10)$. A variação entre tratamentos, quando significativa, foi discriminada através dos testes de Scott \& Knott (ASCPD, severidade final e taxa de progresso da doença) e de Tukey (tamanho de pústulas em plântulas) ao nível de $1 \%$ de probabilidade. Para as variáveis quantificadas também foram realizadas análises de correlação (Teste t), distribuições de freqüências e teste de normalidade (Lilliefors). As análises estatísticas foram realizadas através do programa GENES (Cruz, 1997), e os gráficos foram elaborados através do programa Microsoft Excel 2003.

\section{RESULTADOS E DISCUSSÃO}

Em 2004, no campo experimental da EEA/UFRGS, a ferrugem da folha da aveia foi inicialmente observada em meados de agosto, desenvolvendo-se ao longo do ciclo da cultura por aproximadamente três meses. Através da quantificação dos parâmetros epidemiológicos área sob a curva de progresso da doença (ASCPD), severidade final (SF) e taxa de progresso da doença $(r)$, pôde-se observar que os genótipos avaliados mostraram reações à ferrugem da folha que variaram de forma contínua dentro de extremos de suscetibilidade e de resistência (Figura 1). A análise de variância revelou diferenças significativas entre os genótipos $(\mathrm{P}=0,01)$ quanto aos três parâmetros epidemiológicos citados, e o teste de Lilliefors revelou que estas variáveis ajustam-se significativamente à distribuição normal $(\mathrm{P}=0,01$ e 0,05$)$.

Nos genótipos mais suscetíveis, a severidade final alcançou até 76\% da área foliar, a ASCPD foi de até 781,63 unidades de área (u.a.) e a taxa de progresso da doença foi de até $1,583 \%$ de severidade/dia. Entre os genótipos mais resistentes, a severidade final atingiu de $3 \%$ a $21 \%$, as ASCPDs foram inferiores a 180 u.a. e a taxa de progresso da doença não foi maior que $0,422 \%$ dia. As linhagens 263, 292, 288, 270, 221, 249, 206, 207, 243, 280, 278, 244 e 238 apresentaram os melhores níveis de resistência quantitativa, caracterizada essencialmente por progresso lento da doença, e severidade final e ASCPD reduzidas (Tabela 1). Essas características ficam evidentes quando o progresso da severidade da ferrugem nas referidas linhagens é comparado, por exemplo, ao da linhagem 210, a qual está entre os genótipos mais suscetíveis (Figura 2). Esses resultados estão de acordo com os relatados por Tisian et al. (2004), onde os genótipos 243 e 238 destacaram-se entre os mais resistentes, e os genótipos 210 e 257 estavam entre os mais suscetíveis. Os dados também sugerem que, apesar da intensidade moderada da epidemia ocorrida em 2004, houve repetibilidade e consistência dos dados entre diferentes anos em diferentes condições de ambiente em que estes genótipos foram testados.

O baixo valor naASCPD do genitor suscetível UFRGS 7 chama a atenção na comparação entre os genótipos, pois este aparece em posição semelhante aos genótipos mais resistentes. Este fato parece estar relacionado à redução na freqüência de raças virulentas a UFRGS 7, uma vez que não houve escape da doença no campo, visto que alguns genótipos apresentaram alta severidade no final do ciclo da 
cultura e valores elevados de ASCPD (Tabela 1). É provável que esta observação tenha decorrido da redução da área cultivada com a cultivar UFRGS 7, a qual foi substituída por novas variedades resistentes, pois a população patogênica de $P$. coronata $\mathrm{f}$. sp. avenae tende a adaptar-se aos genes das novas cultivares disponíveis, tendo suas freqüências raciais alteradas ao longo do tempo. Leonard \& Martinelli (2005) relataram alterações nas frequiências de virulência a alguns genes $P c$ de resistência a $P$. coronata f. sp. avenae no sul do Brasil, no período de 1997 a 2003. Os autores constataram que neste período a houve uma elevação na freqüência de virulência aos genes $P c 35, P c 36, P c 40, P c 45, P c 51, P c 52$, $P c 56$ e $P c 59$ e uma redução na freqüência de virulência aos genes $P c 38, P c 39, P c 50, P c 62$ e $P c 63$. Para outros genes, como $P c 46, P c 48$ e $P c 60$, a freqüência de virulência manteve-se relativamente estável no mesmo período.

O possível efeito de uma baixa freqüência de raças de P. coronata f. sp. avenae virulentas a UFRGS 7 também foi evidenciado por Tisian et al. (2004), ao realizar avaliações da ASCPD nesta mesma população em dois anos consecutivos. Os autores também observaram menor ASCPD em UFRGS 7 quando comparada a UFRGS 910906. No entanto, pressupõe-se que, se UFRGS 7 voltasse a ser cultivada em grandes áreas, seus níveis de ferrugem da folha voltariam a ser elevados, pois as raças virulentas a este genótipo rapidamente voltariam a ocorrer em alta freqüência. Por este motivo, o estudo do conjunto de componentes da resistência quantitativa em condições controladas pode auxiliar na seleção de linhagens com este tipo de resistência, de forma mais segura.

A despeito disso, no ambiente onde o ensaio foi conduzido em 2004 houve alta pressão de inóculo e condições climáticas favoráveis ao desenvolvimento de epidemias de ferrugem, o que evidencia que o genitor parcialmente resistente UFRGS 910906 conferiu bons níveis de resistência quantitativa à progênie. Várias linhagens filhas destacaram-se por apresentar níveis de resistência quantitativa superiores ao genitor parcialmente resistente, o que indica que nestas houve uma combinação de componentes da resistência parcial altamente favorável. Ainda, cabe ressaltar que UFRGS 910906 tem mostrado em campo valores intermediários e constantes de ASCPD, em relação a testemunhas suscetíveis, ao longo dos vários anos em que tem sido testada (Thomé, 1999; Chaves, 2004a; Barbosa, 2002; Tisian et al., 2004).

O comprimento de pústulas é relatado como um importante componente da resistência parcial na interação P. hordei $\mathrm{x}$ cevada (Parlevliet, 1979). Brake \& Irwin (1992) relatam que, para a interação $P$. coronata $\mathrm{x}$ aveia, a cultivar 'Ascenção' (parcialmente resistente) apresentou pústulas relativamente grandes, embora, em uma densidade muito baixa. Ainda, genótipos de trigo com o gene de resistência de planta adulta $\operatorname{Lr34}$ são caracterizados por apresentar poucas pústulas, porém estas podem ter tamanho relativamente grande, principalmente próximo à bainha das folhas (Dyck \& Samborski, 1979).
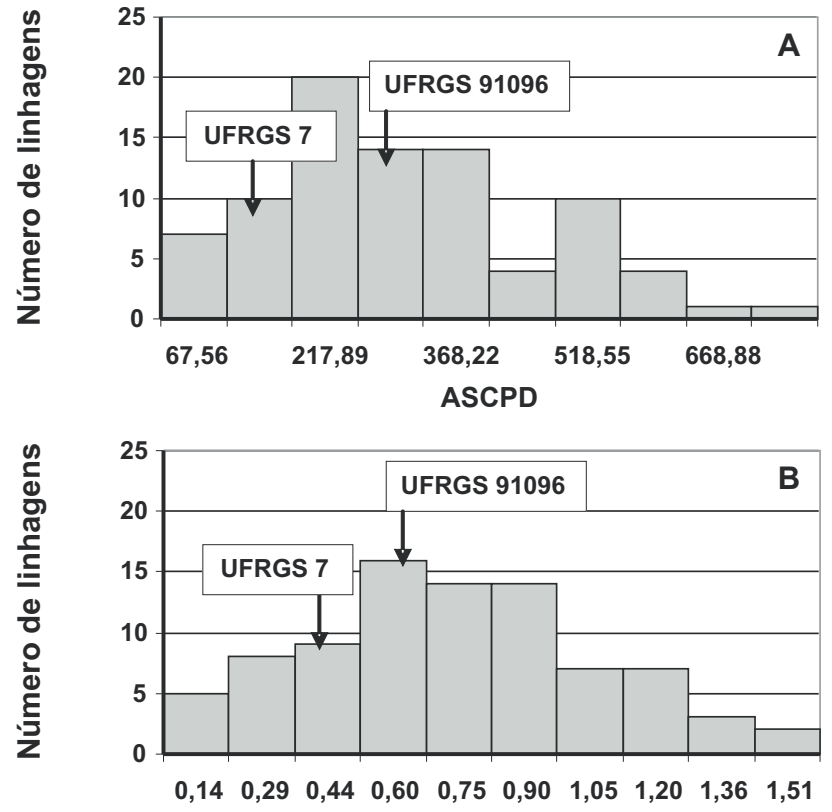

Taxa de progresso da ferrugem da folha (\%A.F.A/dia)

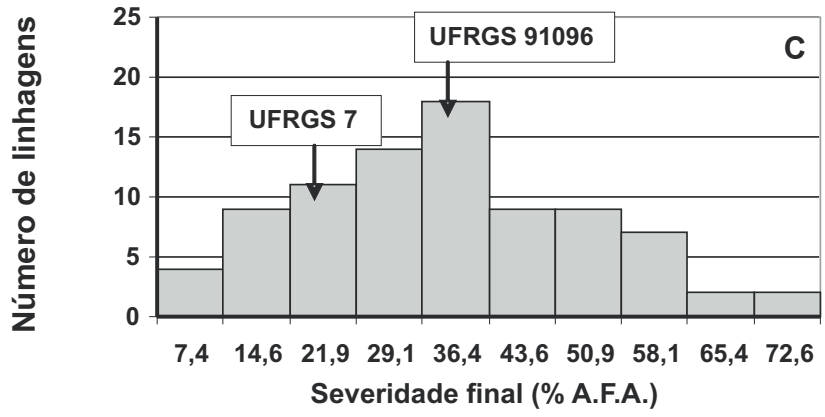

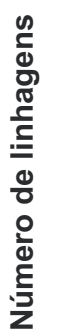

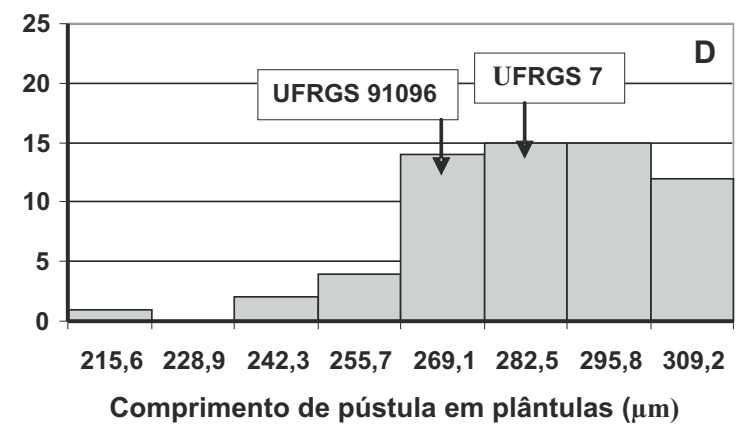

FIG. 1 - Distribuição de freqüências dos genótipos de aveia branca UFRGS 7, UFRGS 910906 e de 83 linhagens $\mathrm{F}_{6: 10}$ oriundas de seu cruzamento com dados de: A) área sob a curva de progresso da doença (ASCPD), B) taxa de progresso da doença ( $r=\%$ Área Foliar Afetada/dia), C) severidade final, e D) comprimento de pústulas em plântulas $(\mu \mathrm{m})$.

A ANOVA do comprimento de pústulas em fase de planta adulta demonstrou não haver diferenças significativas tanto entre genótipos quanto entre as diferentes folhasbandeira avaliadas. A interação genótipo $\mathrm{x}$ folha bandeira também não foi significativa. No estádio de plântula, a 
TABELA 1 - Comparação entre genótipos de aveia branca (UFRGS 7, UFRGS 910906 e 83 linhagens $\mathrm{F}_{6: 10}$ oriundas de seu cruzamento) quanto à área sob a curva de progresso da doença (ASCPD), taxa de progresso da doença ( $r=\%$ Área Foliar Afetada/dia), severidade final (\% Área Foliar Afetada Final) e comprimento de pústulas $(\mu \mathrm{m})$ no estádio de plântula

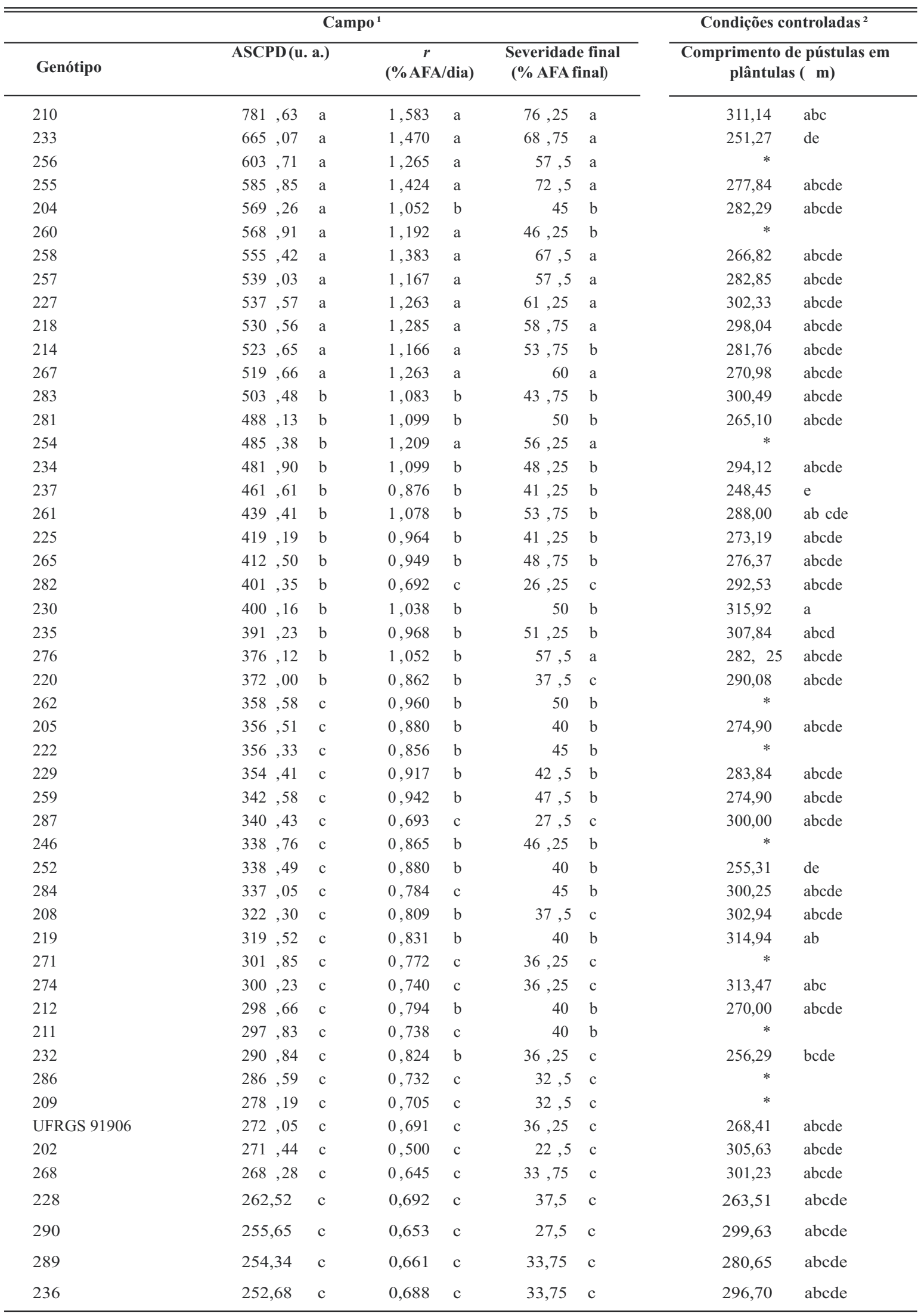


Cont.

\begin{tabular}{|c|c|c|c|c|c|c|c|c|}
\hline 240 & 246,54 & $\mathrm{c}$ & 0,672 & $\mathrm{c}$ & 35 & $\mathrm{c}$ & $*$ & \\
\hline 224 & 240,84 & $\mathrm{c}$ & 0,600 & $\mathrm{c}$ & 32,5 & $\mathrm{c}$ & 247,96 & $\mathrm{e}$ \\
\hline 285 & 238,44 & $\mathrm{c}$ & 0,651 & $\mathrm{c}$ & 35 & $\mathrm{c}$ & $*$ & \\
\hline 273 & 231,39 & $\mathrm{c}$ & 0,621 & $\mathrm{c}$ & 30 & $\mathrm{c}$ & $*$ & \\
\hline 250 & 230,55 & $\mathrm{c}$ & 0,653 & $\mathrm{c}$ & 28,75 & $\mathrm{c}$ & 302,45 & abcde \\
\hline 241 & 225,24 & $\mathrm{c}$ & 0,644 & $\mathrm{c}$ & 31,25 & $\mathrm{c}$ & 306,74 & abcde \\
\hline 269 & 223,58 & $\mathrm{c}$ & 0,524 & $\mathrm{c}$ & 25 & $\mathrm{c}$ & 304,90 & abcde \\
\hline 272 & 222,01 & $\mathrm{c}$ & 0,599 & $\mathrm{c}$ & 31,25 & $\mathrm{c}$ & $*$ & \\
\hline 216 & 220,33 & $\mathrm{c}$ & 0,611 & $\mathrm{c}$ & 33 & $\mathrm{c}$ & 265,96 & abcde \\
\hline 247 & 220,11 & $\mathrm{c}$ & 0,422 & $\mathrm{~d}$ & 21,25 & $\mathrm{~d}$ & $*$ & \\
\hline 275 & 217,28 & $\mathrm{c}$ & 0,531 & $\mathrm{c}$ & 23,75 & $\mathrm{c}$ & 267,92 & abcde \\
\hline 248 & 215,13 & $\mathrm{c}$ & 0,551 & $\mathrm{c}$ & 28,75 & $\mathrm{c}$ & 280,78 & abcde \\
\hline 251 & 208,52 & $\mathrm{c}$ & 0,566 & $\mathrm{c}$ & 30 & $\mathrm{c}$ & 292,29 & abcde \\
\hline 264 & 208,47 & $\mathrm{c}$ & 0,593 & $\mathrm{c}$ & 30 & $\mathrm{c}$ & 268,41 & abcde \\
\hline 242 & 201,03 & $\mathrm{c}$ & 0,537 & $\mathrm{c}$ & 25 & $\mathrm{c}$ & 289,10 & abcde \\
\hline 295 & 195,44 & $\mathrm{c}$ & 0,515 & $\mathrm{c}$ & 25 & $\mathrm{c}$ & $*$ & \\
\hline 266 & 195,19 & $\mathrm{c}$ & 0,510 & $\mathrm{c}$ & 23,75 & $\mathrm{c}$ & $*$ & \\
\hline UFRGS 7 & 185,68 & $\mathrm{~d}$ & 0,511 & $\mathrm{c}$ & 21,75 & $\mathrm{c}$ & 288,86 & abcde \\
\hline 277 & 172,86 & $\mathrm{~d}$ & 0,498 & $\mathrm{c}$ & 26,25 & $\mathrm{c}$ & 305,27 & abcde \\
\hline 291 & 167,59 & $\mathrm{~d}$ & 0,360 & $\mathrm{~d}$ & 18 & $\mathrm{~d}$ & $*$ & \\
\hline 245 & 161,78 & $\mathrm{~d}$ & 0,458 & $\mathrm{c}$ & 22,5 & $\mathrm{c}$ & 285,68 & abcde \\
\hline 239 & 154,47 & $\mathrm{~d}$ & 0,428 & $\mathrm{~d}$ & 23,75 & $\mathrm{c}$ & $*$ & \\
\hline 263 & 146,22 & $\mathrm{~d}$ & 0,419 & $\mathrm{~d}$ & 20,5 & $\mathrm{~d}$ & $*$ & \\
\hline 292 & 122,05 & $\mathrm{~d}$ & 0,310 & $\mathrm{~d}$ & 13,75 & $\mathrm{~d}$ & 283,23 & abcde \\
\hline 288 & 115,96 & $\mathrm{~d}$ & 0,301 & $\mathrm{~d}$ & 11,5 & $\mathrm{~d}$ & 260,33 & abcde \\
\hline 270 & 108,51 & $\mathrm{~d}$ & 0,277 & $\mathrm{~d}$ & 12,5 & $\mathrm{~d}$ & 271,59 & abcde \\
\hline 221 & 107,42 & $\mathrm{~d}$ & 0,273 & $\mathrm{~d}$ & 11,5 & $\mathrm{~d}$ & $*$ & \\
\hline 249 & 105,23 & $\mathrm{~d}$ & 0,305 & $\mathrm{~d}$ & 18 & $\mathrm{~d}$ & 276,49 & abcde \\
\hline 206 & 99,64 & $\mathrm{~d}$ & 0,272 & $\mathrm{~d}$ & 13,75 & $\mathrm{~d}$ & 291,80 & abcde \\
\hline 207 & 97,32 & $\mathrm{~d}$ & 0,250 & $\mathrm{~d}$ & 11,25 & $\mathrm{~d}$ & 304,17 & abcde \\
\hline 243 & 74,73 & $\mathrm{~d}$ & 0,213 & $\mathrm{~d}$ & 11,25 & $\mathrm{~d}$ & 287,51 & abcde \\
\hline 280 & 74,14 & $\mathrm{~d}$ & 0,205 & $\mathrm{~d}$ & 8,75 & $\mathrm{~d}$ & $*$ & \\
\hline 278 & 62,16 & $\mathrm{~d}$ & 0,166 & $\mathrm{~d}$ & 7,5 & $\mathrm{~d}$ & 311,14 & $a b c$ \\
\hline 244 & 41,22 & $\mathrm{~d}$ & 0,108 & $\mathrm{~d}$ & 6,75 & $\mathrm{~d}$ & 269,63 & abcde \\
\hline 238 & 29,98 & $\mathrm{~d}$ & 0,063 & $\mathrm{~d}$ & 3,75 & $\mathrm{~d}$ & 292,90 & abcde \\
\hline Média & 306,30 & & 0,740 & & 35,56 & & 285,41 & \\
\hline C.V. (\%) & 14,08 & & 1,66 & & 13,63 & & 22,86 & \\
\hline
\end{tabular}

${ }^{1}$ Médias seguidas por letras distintas diferem entre si pelo teste de Scott \& Knott ao nível de 1\% de probabilidade.

${ }^{2}$ Médias seguidas por letras distintas diferem entre si pelo teste de Tukey ao nível de 1\% de probabilidade

* Informação não disponível.

ANOVA revelou diferenças significativas entre os genótipos $(\mathrm{P}=0,01)$, sendo que o comprimento médio de lesões variou de forma contínua entre os extremos observados $(247,96 \mu \mathrm{m}$, na linhagem 224 , a $315,92 \mu \mathrm{m}$, na linhagem 230) (Tabela 1). O teste de Lilliefors revelou que a variação no tamanho de pústulas em plântulas também se ajusta significativamente à distribuição normal $(\mathrm{P}=0,01)$ (Figura 1). Os três parâmetros epidemiológicos avaliados no campo tiveram alta correlação positiva entre si (Figura 3), entretanto o tamanho de pústulas em plântulas, embora também tenha apresentado intervalo contínuo de variação, não demonstrou estar associado com nenhuma dessas variáveis (Tabela 2). Além disso, a discriminação da variação entre tratamentos
(Tabela 1) evidenciou que este componente de resistência não diferenciou os genótipos com maior nível de resistência parcial daqueles suscetíveis.

Os resultados deste trabalho em relação ao tamanho de pústulas concordam com os de Chaves et al. (2004c), os quais constataram que, na interação $P$. coronata $\mathrm{x}$ aveia, existe baixa correlação entre os componentes da resistência parcial com a ASCPD em condições de campo. Os autores sugerem que a resistência neste patossistema parece ser conferida pela ação conjunta dos componentes de resistência, havendo ainda, a possibilidade de mecanismos diferenciados atuarem em cada genótipo. Fato semelhante é observado na resistência parcial à ferrugem linear do trigo, causada 


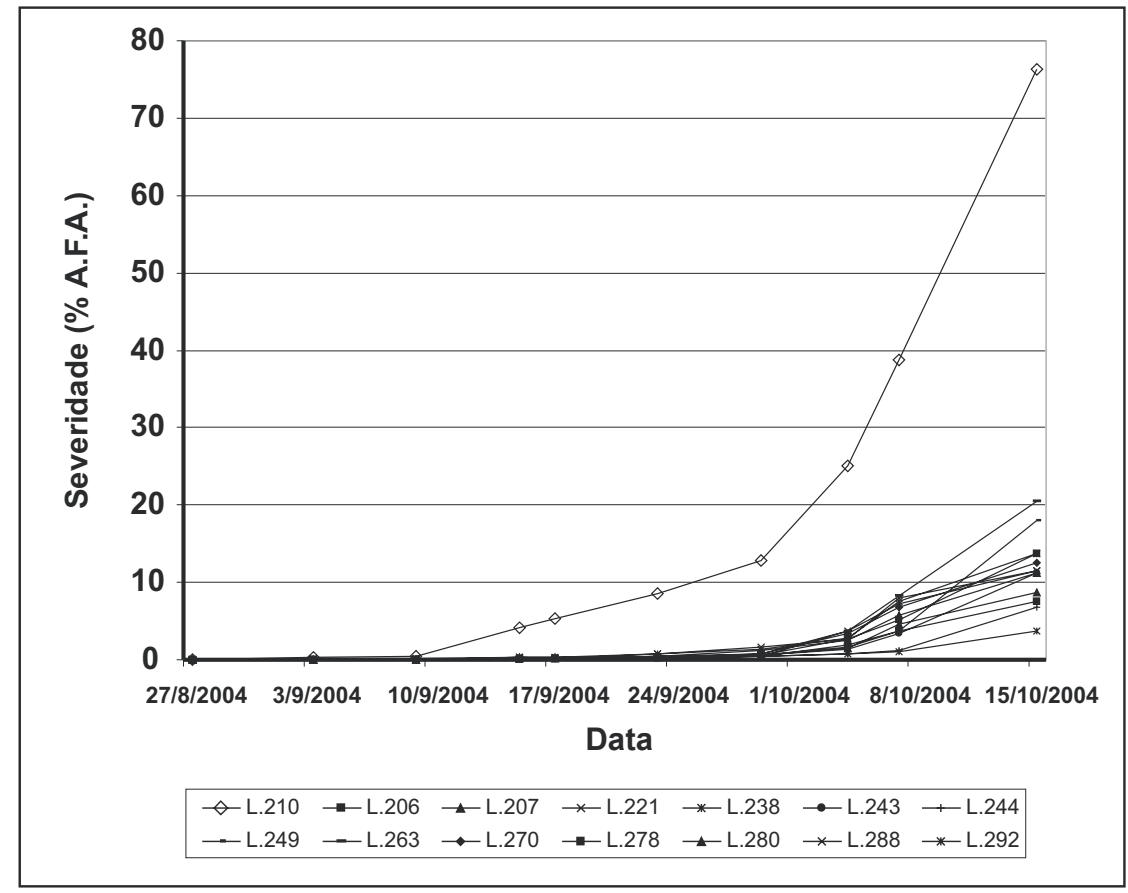

FIG. 2 - Curvas de progresso da severidade (\% Área Foliar Afetada) da ferrugem da folha em condições de campo em linhagens $\mathrm{F}_{6: 10}$ de aveia branca oriundas do cruzamento UFRGS 7 x UFRGS 910906. por $P$. striiformis, onde cada componente envolvido na resistência parece ser controlado por diferentes genes (Milus \& Line, 1986).

Camargo (1995) cita que o número de genes envolvidos no condicionamento de um caráter é proporcional à distribuição da variação entre genótipos, pois quanto maior o número de genes, maior será também o número das diferentes combinações possíveis entre eles, o que aumenta, por sua vez, a amplitude da distribuição fenotípica. A natureza poligênica da herança da resistência parcial à ferrugem da folha conferida pela linhagem UFRGS 910906 fica evidenciada pela continuidade da distribuição fenotípica observada em todas as variáveis analisadas no presente trabalho. Thomé (1999) afirmou que vários genes de pequeno efeito estavam envolvidos na herança genética dos componentes de resistência avaliados na geração $\mathrm{F}_{2}$ deste mesmo cruzamento, com grande contribuição de efeitos de dominância (interação de alelos do mesmo gene, onde o gene com efeito dominante pode mascarar o alelo com efeito recessivo) e efeito epistático. Além disto, Barbosa (2002) identificou QTLs associados à resistência parcial à ferrugem da folha em duas gerações desta mesma população (cinco QTLs na geração $F_{2}$ e três na geração $\mathrm{F}_{6}$ ), o que corrobora o aspecto quantitativo da resistência de UFRGS 910906.

Segregação transgressiva diz respeito ao aparecimento, em gerações segregantes, de indivíduos que estão fora do intervalo dos genitores no que se refere à dada característica. A segregação transgressiva para resistência e para suscetibilidade é um indicativo de que a resistência parcial é governada por vários genes de pequeno efeito (Hautea et al., 1987). Caso não haja segregação transgressiva entre o cruzamento de uma variedade com resistência parcial e uma suscetível, deve-se presumir que o genitor suscetível não contribui com nenhum gene de resistência detectável (Milus \& Line, 1986; Zhang et al., 2001). De acordo com Mariot et al., 1998, há ocorrência de segregação transgressiva, em cruzamentos interespecíficos, para resistência à ferrugem do colmo e da folha em aveia. Resultados semelhantes foram observados em trigo, para a resistência parcial ao oídio (Hautea et al.,1987) e resistência parcial à ferrugem linear (Milus \& Line, 1986; Navabi et al., 2004). A segregação transgressiva observada em todas as variáveis analisadas é mais um indício da natureza poligênica da resistência parcial à ferrugem da folha da aveia.

O nível de resistência quantitativa encontrado na população estudada ainda parece estar abaixo do ideal para o controle efetivo da doença, especialmente no sul do Brasil, onde as condições de ambiente e de pressão de inóculo são extremamente favoráveis ao desenvolvimento de epidemias severas e de longa duração. Entretanto, os genótipos que se destacaram em resistência são de grande utilidade em programas de melhoramento genético como fontes de resistência, onde as estratégias de acúmulo de alelos quantitativos favoráveis ou de associação de resistência total e parcial podem ser exploradas. Além de sua importância como fontes de resistência, esses genótipos também são potencialmente úteis para a investigação dos mecanismos envolvidos na expressão da resistência quantitativa à ferrugem da folha da aveia. 

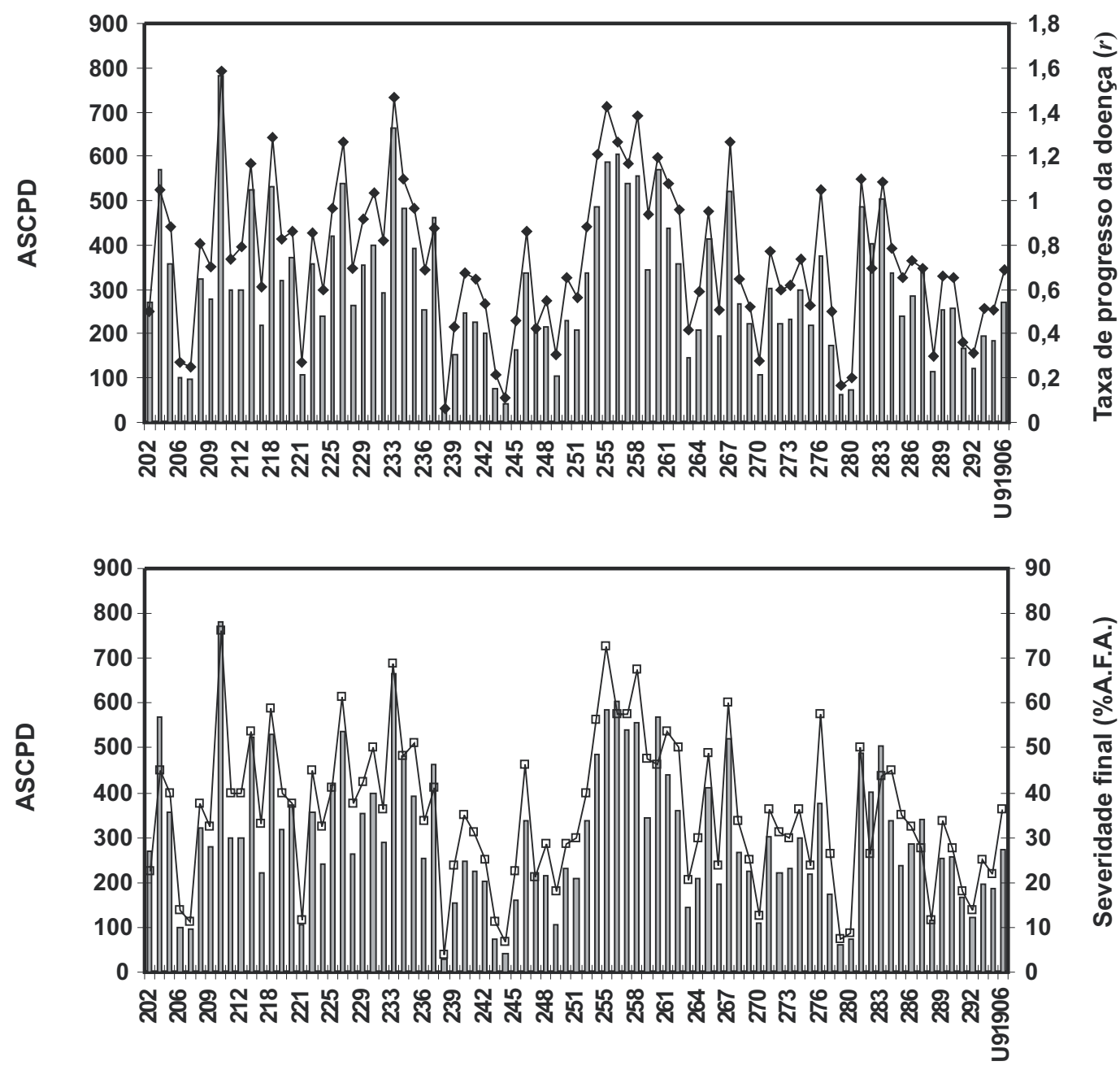

व்

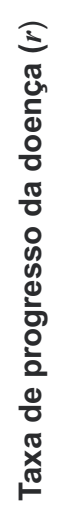

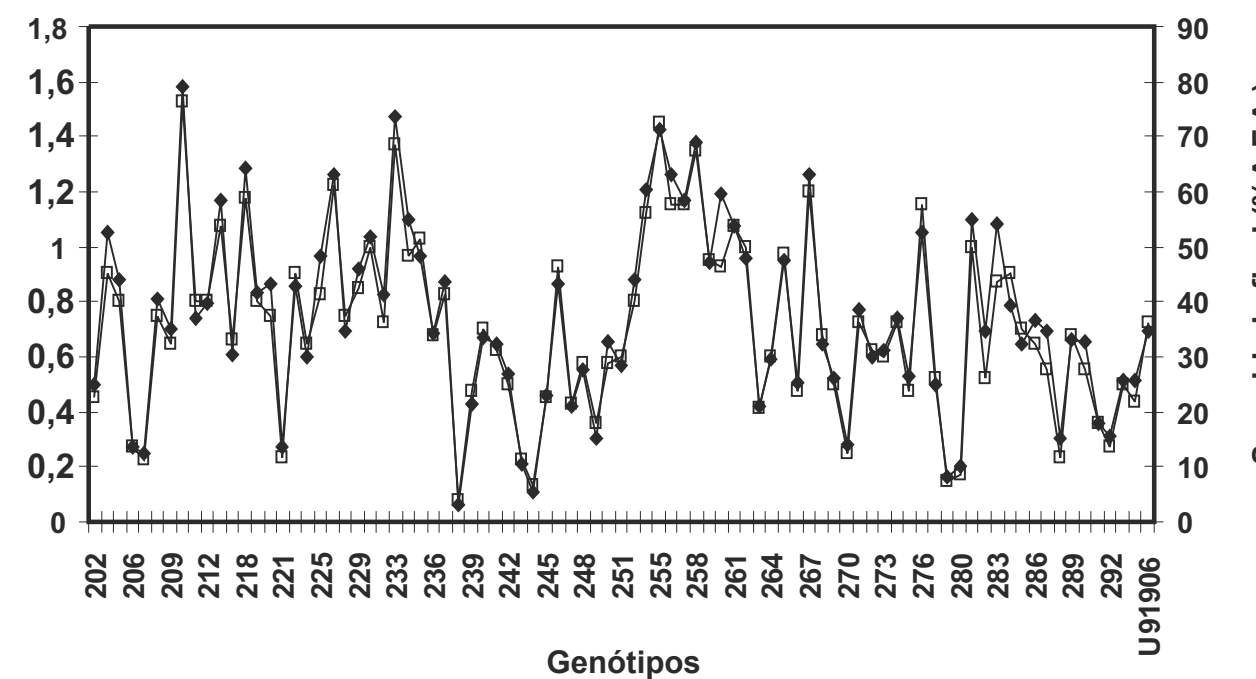

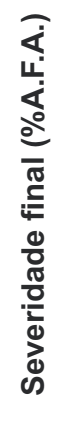

FIG. 3 - Correlação entre a área sob a curva de progresso da doença (ASCPD), taxa de progresso da doença ( $r=\%$ Área Foliar Afetada/dia), severidade final (\% Área Foliar Afetada) nos genótipos de aveia branca UFRGS 7, UFRGS 910906 e 83 linhagens $\mathrm{F}_{6: 10}$ oriundas de seu cruzamento. 
TABELA 2 - Coeficiente de correlação entre as variáveis área sob a curva de progresso da doença (ASCPD), taxa de progresso da doença $(r)$, severidade final (SF) e comprimento de pústulas no estádio de plântula $(\mathrm{CP})$ nos genótipos de aveia branca UFRGS 7, UFRGS 910906 e 83 linhagens $F_{6: 10}$ oriundas de seu cruzamento

\begin{tabular}{lccc}
\hline \hline Variáveis & $\boldsymbol{r}$ & $\mathbf{S F}$ & $\mathbf{C P}$ \\
\hline ASCPD & $0,971^{* *}$ & $0,9344^{* *}$ & $-0,0795 \mathrm{~ns}$ \\
$r$ & & $0,9826^{* *}$ & $-0,0949 \mathrm{~ns}$ \\
SF & & & $-0,1284 \mathrm{~ns}$ \\
\hline
\end{tabular}

ns=não significativo, ${ }^{* *}=$ significativo a $1 \%$ de probabilidade pelo Teste t.

\section{AGRADECIMENTOS}

A primeira autora agradece ao Conselho Nacional de Desenvolvimento Científico e Tecnológico - CNPq pela concessão de bolsa de estudo.

\section{REFERÊNCIAS BIBLIOGRÁFICAS}

Barbosa MM (2002) Genética e mapeamento molecular da resistência parcial à ferrugem da folha da aveia (Avena sativa L.). Tese de Doutorado. Universidade Federal do Rio Grande do Sul. Porto Alegre RS.

Brake VM, Irwin JAG (1992) Partial resistance of oats to $P$. coronata f. sp. avenae. Australian Journal of Agricultural Research 43:1217-27.

Camargo LEA (1995) Análise genética da resistência e da patogenicidade. In: Bergamin Filho A, Kimati H, Amorim L (Eds.) Manual de Fitopatologia. São Paulo SP. Editora Agronômica Ceres. v.1. pp. 470-492.

Chaves MS, Martinelli JA, Federizzi LC (2004a) Resistência quantitativa à ferrugem da folha em genótipos de aveia branca: I - Caracterização da reação em condições de campo. Fitopatologia Brasileira 29:35-42.

Chaves MS, Martinelli JA, Federizzi LC (2004b) Resistência quantitativa à ferrugem da folha em genótipos de aveia branca: II - Avaliação de componentes de resistência. Fitopatologia Brasileira 29:43-51.

Chaves MS, Martinelli JA, Federizzi LC (2004c) Resistência quantitativa à ferrugem da folha em genótipos de aveia branca: III - Correlação de componentes de resistência entre si e com a intensidade de doença no campo. Fitopatologia Brasileira 29:197200 .

Cruz CD (1997) Programa genes: aplicativo computacional em genética e estatística. Viçosa MG. Editora UFV.

Cruz RP, Federizzi LC, Milach SCK (1999) Severidade da ferrugem da folha e seus efeitos sobre caracteres da panícula de aveia. Pesquisa Agropecuária Brasileira 34:543-551.

Dyck PL, Samborski DJ (1979) Adult-plant leaf rust resistance in
PI 250413, an introduction of common wheat. Canadian Journal of Plant Science 59:329-332.

Hautea RA, Coffman WR, Sorrells ME, Bergstrom GC (1987) Inheritance of partial resistance to powdery mildew in spring wheat. Theoretical and Applied Genetics 73:609-615.

Kulcheski FR, Graichen FAS, Delatorre CA, Martinelli JA, Pacheco MT (2006) Evolução da resistência parcial à ferrugem da folha na população de aveia branca UFRGS 7 X UFRGS 910906. XXVI Reunião da Comissão Brasileira de Pesquisa de Aveia. Guarapuava PR. Resultados Experimentais 26:61-64.

Leonard KJ (2002) Oat lines with effective adult plant resistance to crown rust. Plant Disease 86:593-598.

Leonard KJ, Martinelli JA (2005) Virulence of oat crown rust in Brazil and Uruguay. Plant Disease 89:802-808.

Mariot MP, Sereno MJCM, Federizzi LC, Carvalho FIF (1998) Avaliação da incidência de ferrugem da folha e ferrugem do colmo em cruzamento inter-específico em aveia. Pesquisa Agropecuária Brasileira 33:1481-1486.

Martinelli JA, Federizzi LC, Benedetti AC (1994) Redução no rendimento de grãos de aveia em função da severidade da ferrugem da folha. Summa Phytopathologica 40:116-118.

Milus EA, Line RF (1986) Number of genes controlling hightemperature, adult-plant resistance to stripe rust in wheat. Phytopathology 76:93-96.

Navabi A, Singh RP, Tewari JP, Briggs KG (2004) Inheritance of high levels of adult-plant resistance to stripe rust in five spring wheat genotypes. Crop Science 44:1156-1162.

Parlevliet JE (1979) Components of resistance that reduce the rate of epidemic development. Annual Review of Phytopathology 17:203-222.

Parlevliet JE (1986) Pleiotropic association of infection frequency and latent period of two barley cultivars partially resistant to barley leaf rust. Euphytica 35:267-272.

Parlevliet JE (1988) Strategies for the utilization of partial resistance for the control of cereal rusts. In: Simmonds NW, Rajaram S (Eds.) Breeding Strategies for Resistance to the Rusts of Wheat. Mexico. CYMMIT. pp. 48-62.

Parlevliet JE (1985) Resistance of the nonrace-specific type. In: Bushnell WR, Roelfs AP (Eds.) The Cereal Rusts. Vol II. Diseases, distribution, epidemiology and control. New York NY. Academic Press. pp. 501-525.

Rees RG, Thompson J.P, Mayer R (1979a) Slow rusting and tolerance to rusts in wheat. The progress and effects of epidemics of Puccinia graminis tritici in selected wheat cultivars. Australian Journal of Agricultural Research 30:403-419.

Rees RG, Thompson JP, Mayer R (1979b) Slow rusting and tolerance to rusts in wheat. The progress and effects of epidemics of Puccinia recondita tritici in selected wheat cultivars. Australian Journal of Agricultural Research 30:421-432.

Shaner G, Finney RE (1977) The effect of nitrogen fertilizationon the expression of slow mildewing resistance in 'Knox' wheat. Phytopathology 67:1051-1056.

Stubbs RW, Prescott JM, Saari EE, Dubin HJ (1986) Manual de metodologia sobre las enfermedades de los cereales. México DF. CYMMIT.

Thomé GCH (1999) Genética e análise molecular da resistência 
Herança da resistência quantitativa à ferrugem da folha em linhagens...

parcial à ferrugem da folha em aveia. Tese de Doutorado. Porto Universidade Federal do Rio Grande do Sul. Alegre RS.

Tisian LM, Milach SCK, Federizzi LC, Martinelli JA, Barbosa MM (2004) Resistência parcial à ferrugem da folha em linhagens recombinantes de aveia. XXIV Reunião da Comissão Brasileira de Pesquisa da Aveia, Pelotas, RS. Resultados Experimentais 24:575-577.
Whal I, Wilcoxson RD, Rowell JB (1980) Slow rusting of wheat and stem rust detected in the glasshouse. Plant Disease 64:54-56.

Zhang ZJ, Yang GH, Li GH, Jin SL, Yang XB (2001) Transgressive segregation, heritability, and number of genes controlling durable resistance to stripe rust in one Chinese and two Italian wheat cultivars. Phytopathology 91:680-686. 